\title{
Does In Utero Exposure to Heavy Maternal Smoking Induce Nicotine Withdrawal Symptoms in Neonates?
}

\author{
VERONIQUE GODDING, CHRISTINE BONNIER, LEON FIASSE, MARIANNE MICHEL, \\ ETIENNE LONGUEVILLE, PATRICK LEBECQUE, ANNIE ROBERT, AND LAURENCE GALANTI \\ Pediatric Pulmonology [V.G., P.L.], Pediatric Neurology [C.B.], Epidemiology [A.R.], Clinical Biology \\ [L.G.], and Cliniques Saint-Luc [V.G., C.B., P.L.], Université Catholique de Louvain, 1200 Brussels; \\ Cliniques de Mont-Godinne [L.G.], Université Catholique de Louvain, 5330 Yvoir; and Pediatrics \\ [L.F., M.M.] and Obstetrics [E.L.], Clinique St-Pierre, 1340 Ottignies, Belgium.
}

\begin{abstract}
ABST
Maternal drug use during pregnancy is associated with fetal
passive addiction and neonatal withdrawal syndrome. Cigarette
smoking- highly prevalent during pregnancy-is associated
with addiction and withdrawal syndrome in adults. We con-
ducted a prospective, two-group parallel study on 17 consecutive
newborns of heavy-smoking mothers and 16 newborns of non-
smoking, unexposed mothers (controls). Neurologic examina-
tions were repeated at days 1,2 , and 5 . Finnegan withdrawal
score was assessed every $3 \mathrm{~h}$ during their first $4 \mathrm{~d}$. Newborns of
smoking mothers had significant levels of cotinine in the cord
blood $(85.8 \pm 3.4$ ng/mL), whereas none of the controls had
detectable levels. Similar findings were observed with urinary
cotinine concentrations in the newborns $(483.1 \pm 2.5 \mu \mathrm{g} / \mathrm{g}$
creatinine versus $43.6 \pm 1.5 \mu \mathrm{g} / \mathrm{g}$ creatinine; $p=0.0001)$.
Neurologic scores were significantly lower in newborns of smok-
ers than in control infants at days 1 ( $22.3 \pm 2.3$ versus $26.5 \pm$
$1.1 ; p=0.0001), 2(22.4 \pm 3.3$ versus $26.3 \pm 1.6 ; p=0.0002)$,
\end{abstract}
Addiction to nicotine is a common feature among HS. The majority of adult smokers are physically dependent on nicotine (1). Physical dependence is responsible for nicotine withdrawal syndrome among self-quitters. In human adults, nicotine withdrawal is characterized by physical, behavioral, and subjective symptoms (2). The neuropharmacologic mechanisms of nicotine withdrawal syndrome are still unclear, but are thought to involve an increased number of nicotine receptors in the CNS (2-4).

Recent surveys indicate that more than $20 \%$ of pregnancies in Europe occur in current smokers $(5,6)$. Approximately 34 to $40 \%$ of pregnant women quit or decrease their smoking during gestation in the United States (7).

Received March 4, 2003; accepted July 23, 2003.

Correspondence: Veronique Godding, M.D., Pneumologie Pediatrique, Departement de Pediatrie, Cliniques UCL St-Luc, 10, av.Hippocrate, 1200 Bruxelles, Belgium; e-mail: godding@mexp.ucl.ac.be

DOI: 10.1203/01.PDR.0000112099.88740.4E and $5(24.3 \pm 2.1$ versus $26.5 \pm 1.5 ; p=0.002)$. Neurologic scores improved significantly from day 1 to 5 in newborns of smokers $(p=0.05)$, reaching values closer to control infants. Withdrawal scores were higher in newborns of smokers than in control infants at days $1(4.5 \pm 1.1$ versus $3.2 \pm 1.4 ; p=0.05)$, $2(4.7 \pm 1.7$ versus $3.1 \pm 1.1 ; p=0.002)$, and $4(4.7 \pm 2.1$ versus $2.9 \pm 1.4 ; p=0.007)$. Significant correlations were observed between markers of nicotine exposure and neurologicand withdrawal scores. We conclude that withdrawal symptoms occur in newborns exposed to heavy maternal smoking during pregnancy. (Pediatr Res 55: 645-651, 2004)
CO, carbon monoxide
HS, heavy smoker
NS, nonsmoker

It is not clear whether fetal passive addiction to nicotine occurs during pregnancy. Indeed, nicotinic acetylcholine receptors are present in the CNS of both animals (8) and humans (9) from the embryonic stage. During smokers' pregnancy, the fetus is chronically exposed to nicotine concentrations that are $15 \%$ higher than in the maternal bloodstream (10). The adult metabolism of nicotine is rapid, its half-life being $2 \mathrm{~h}$ (11). Studies of nicotine levels in newborns from smoking mothers have shown very low or undetectable levels, suggesting rapid fetal metabolism of nicotine (12).

In most maternity wards, smoking is prohibited during labor. Therefore, acute deprivation of nicotine takes place on maternal admission to the labor room, creating conditions for neonatal nicotine withdrawal.

Withdrawal syndromes in newborns have been characterized with other drugs of abuse, such as opiates and benzodiazepines (13). Conflicting data about nicotine withdrawal in newborns are found in previous studies. Newborns of smoking mothers 
were shown to have impaired performances at days 1 and 2 when compared with newborns of nonsmoking mothers (14). However, these findings were not supported by biologic monitoring of nicotine exposure in mothers and their offspring. Recently, a pilot study described intermediate Finnegan withdrawal scores in a small number of newborns with high urinary cotinine levels (15). In contrast, some clinical studies did not confirm the existence of neonatal nicotine withdrawal symptoms in humans (16) and animals (17).

We wanted to study prospectively the effects of acute cessation of exposure to maternal smoking on normal newborns of HS ( $>10$ cigarettes/d throughout pregnancy) compared with normal newborns of NS, unexposed mothers. We evaluated the effects, if any, of nicotine withdrawal, using a detailed neurologic examination of the newborns, a validated withdrawal score, and a biologic monitoring of exposure to maternal smoking. Given the nicotine half-life, neurologic examination of the newborns was performed on days 1,2 , and 5 , whereas Finnegan withdrawal score was recorded every $3 \mathrm{~h}$ during days $1,2,3$, and 4 . Maternal smoking was evaluated using a score of physical dependence and a biologic monitoring related to immediate smoking ( $\mathrm{CO}$ in expired air), recent smoking (urinary cotinine concentration, $48 \mathrm{~h}$ ), and chronic smoking (salivary thiocyanates, $3 \mathrm{wk}$ ). Intrauterine exposure was measured using cord blood cotinine levels and neonatal urinary cotinine concentration (48 h).

\section{METHODS}

Population. We recruited $21 \mathrm{HS}$ pregnant women and $18 \mathrm{NS}$ unexposed pregnant women, before delivery, at the antenatal clinic of the Clinique St-Pierre, Ottignies, Belgium. The women were recruited during eight periods of $2 \mathrm{wk}$, during which nursing staff was available to assess the withdrawal scores. All the pregnancies had been uneventful. All the deliveries took place between 38 and $40 \mathrm{wk}$ of gestation and were considered normal. None of the births occurred by cesarean section. None of the newborns needed resuscitation. One newborn of a smoking mother was excluded because his birth weight was less than $2500 \mathrm{~g}$. Three HS and two NS refused to take part in the study because they wanted an early discharge.

The study protocol was approved by the Ethics Committee of the Clinique St-Pierre, Ottignies. All the mothers gave written informed consent.

Neurologic evaluation. Detailed neurologic examinations were carried out according to widely accepted recommendations $(18,19)$. All examinations were performed by the same investigator (L.F.), teamed with the pediatric neurologist (C.B.), blind to the smoking status of the mothers. Alertness, spontaneous motility, muscle tone, and primary reflexes were assessed at days 1,2 , and 5 .

Alertness was evaluated by the newborn's response to arousal maneuvers and by its spontaneous and provoked motility. Level of alertness, spontaneous motility, eye opening, and tendon reflexes were each scored out of two, the maximum subtotal therefore being eight.

Muscle tone was evaluated as follows. Neck muscle tone was studied using the pull-to-sit maneuver. Passive limb tone was assessed in quiet repose by adductor angle, popliteal angle, and feet dorsal flexion. Evaluation of trunk tone was performed by ventral and lateral suspensions. Each of these specific maneuvers was scored out of two and the maximum subtotal came to 10 .

For primary reflexes, Moro and sucking reflexes were scored out of two, palmar and plantar grasping, tonic neck response, cardinal points reflex, and placing and stepping reactions were scored out of one, and the maximum subtotal came to10. The maximum possible total for the three categories came to 28 .

Finnegan withdrawal score. Finnegan score is a validated score previously designed to evaluate withdrawal symptoms in newborns exposed to opiates during pregnancy (20). The score evaluates the CNS function, the metabolic, vasomotor, and respiratory functions, and the gastrointestinal system (Table 1). Two consecutives scores greater than eight indicate withdrawal syndrome.

Finnegan score was measured every $3 \mathrm{~h}$ from day 1 to 4 by the nursing staff. The mean value for each day was calculated.

Monitoring of cigarette smoking. A 7-mL sample of cord blood was obtained from all subjects. Urine samples were obtained from mothers and babies during the first $48 \mathrm{~h}$. A sample of saliva was obtained from the mothers at the same time. $\mathrm{CO}$ in expired air was determined in the mothers during the first $72 \mathrm{~h}$ after delivery (CO-tester, FIM, Lyon, France). A different investigator (V.G.) administered a smoking questionnaire to the mothers, including a six-item Fagerström score for physical dependence (21) (Table 2) and a personal history of smoking.

Biologic measurements. Blood samples were first treated with trichloroacetic acid (Sigma, St. Louis, MO) to precipitate proteins. Deproteinized plasma or urinary cotinine concentration was then measured after chloroform (Sigma) extraction by HPLC. Analyses were carried out using a Waters Alliance 2690 HPLC separation module (Waters, Milford, MA) equipped with a multiple wavelength detector and a (Millenium 210) processing module. The stationary and mobile phases consisted in a reversed-phase column (Inertsil 5 ODS-3, Chrompack, Bergen op Zoom, The Netherlands,) and in acetonitrile in phosphate buffer, $0.05 \mathrm{M}, \mathrm{pH} 4.3$ (Sigma), respectively (22). The coefficient of variation remained below $5 \%$. The detection limit was $0.010 \mu \mathrm{g} / \mathrm{mL}$. Results were standardized to urinary creatinine measured by Jaffe reaction on Hitachi 747 (Roche, Mannheim, Germany). Discriminated urinary cutoff value between smoker and nonsmoker was fixed at $50 \mu \mathrm{g} / \mathrm{g}$ creatinine.

Salivary thiocyanates were measured by spectrophotometry after addition of ferric chloride (Sigma) according to the method described by Bowler (23).

Statistical methods. Results were expressed as mean \pm SD for normally distributed variables and as geometric means \pm SD for log-normally distributed variables. Log-distributed variables were log-transformed before performing any statistical test. Comparisons between exposed and unexposed newborns were carried out using unpaired $t$ test for continuous variables and Fisher exact test $p$ value for discrete variables. Neurologic and Finnegan scores were submitted to an ANOVA with a repeated measurement factor (day-to-day measurement) 
Table 1. Finnegan score

\begin{tabular}{|c|c|c|c|c|c|c|c|c|c|}
\hline Signs and symptoms & Score & $08 \mathrm{~h}$ & $11 \mathrm{~h}$ & $14 \mathrm{~h}$ & $17 \mathrm{~h}$ & $20 \mathrm{~h}$ & $23 \mathrm{~h}$ & $02 \mathrm{~h}$ & $05 \mathrm{~h}$ \\
\hline High-pitched cry & 2 & & & & & & & & \\
\hline Continuous high-pitched cry & 3 & & & & & & & & \\
\hline Sleeps less than $1 \mathrm{~h}$ after feeding & 3 & & & & & & & & \\
\hline Sleeps less than $3 \mathrm{~h}$ after feeding & 1 & & & & & & & & \\
\hline Hyperactive Moro reflex & 2 & & & & & & & & \\
\hline Markedly hyperactive Moro reflex & 3 & & & & & & & & \\
\hline Mild tremors when undisturbed & 3 & & & & & & & & \\
\hline Marked tremors when undisturbed & 4 & & & & & & & & \\
\hline Generalized convulsions & 5 & & & & & & & & \\
\hline Excoriations & 1 & & & & & & & & \\
\hline Sweating & 1 & & & & & & & & \\
\hline Fever less than $38.2^{\circ} \mathrm{C}$ & 1 & & & & & & & & \\
\hline Sneezing & 1 & & & & & & & & \\
\hline Respiratory rate over 60 minutes & 1 & & & & & & & & \\
\hline Respiratory rate over 60 minutes + retractions & 2 & & & & & & & & \\
\hline Frantic sucking of fists & 1 & & & & & & & & \\
\hline Regurgitation & 2 & & & & & & & & \\
\hline Poor feeding & 2 & & & & & & & & \\
\hline Projectile vomiting & 3 & & & & & & & & \\
\hline Loose stools & 2 & & & & & & & & \\
\hline Watery stools & 3 & & & & & & & & \\
\hline Dehydration & 2 & & & & & & & & \\
\hline Total score & & & & & & & & & \\
\hline
\end{tabular}

Finnegan score for neonatal abstinence, adapted from Finnegan (20) and Suresh (23a).

Table 2. Fagerström test for nicotine dependence

\begin{tabular}{|c|c|c|}
\hline Questions & Answers & Points \\
\hline \multirow{3}{*}{$\begin{array}{l}\text { 1. How soon after you wake up do you smoke your first } \\
\text { cigarette? }\end{array}$} & Within 5 min & 3 \\
\hline & $6-10 \mathrm{~min}$ & 2 \\
\hline & After $60 \mathrm{~min}$ & 0 \\
\hline $\begin{array}{l}\text { 2. Do you find it difficult to refrain from smoking in places } \\
\text { where it is forbidden? }\end{array}$ & Yes & 1 \\
\hline 3. Which cigarette would you hate most to give up? & All others & 0 \\
\hline \multirow[t]{4}{*}{ 4. How many cigarettes/d do you smoke? } & 10 or fewer & 0 \\
\hline & $11-20$ & 1 \\
\hline & $21-30$ & 2 \\
\hline & 31 or more & 3 \\
\hline $\begin{array}{l}\text { 5. Do you smoke more frequently during the first hours } \\
\text { after waking than during the rest of the day? }\end{array}$ & Yes & 1 \\
\hline $\begin{array}{l}\text { 6. Do you smoke if you are so ill that you are in bed most } \\
\text { of the day? }\end{array}$ & No & 0 \\
\hline
\end{tabular}

CPermission to use this scale for other than research purposes should be obtained from K.O. Fagerström (21).

and a grouping factor (exposed or unexposed babies). Significant results led us to perform multiple comparisons, using paired or unpaired $t$ tests, without correcting $p$ values for multiple testing. Correlations were assessed using the Pearson's cross-product coefficient. All tests were two-sided and $p$ values are reported. The statistical significance level was set at 0.05 .

\section{RESULTS}

Seventeen of the pregnant women were HS, having smoked a mean of $27 \pm 11$ cigarettes/d before pregnancy. During pregnancy, their smoking habits decreased significantly, with a mean of $18.6 \pm 5.7$ cigarettes $/ \mathrm{d}(p=0.025)$. None of the NS 
mothers had smoked cigarettes or been exposed to environmental tobacco smoke during pregnancy (Table 3).

A strict nonsmoking policy prevailed both in the maternity ward and in the delivery room. Although smoking mothers did smoke while hospitalized, they refrained from smoking in their rooms and in the maternity ward. Instead, smoking took place in the smoking area of the hospital or outdoors. The newborns were not exposed to environmental smoking during the study. None of the mothers studied used any drug of abuse or alcohol. Their caffeine intake was low and did not depend on whether or not they were smokers.

Smoking habits in mothers. Evaluation of maternal smoking included markers of long-term smoking (salivary thiocyanates, $3 \mathrm{wk}$ ), recent smoking (urinary cotinine, $48 \mathrm{~h}$ ), and of very recent smoking ( $\mathrm{CO}$ in expired air, $3 \mathrm{~h}$ ). The duration of smoking and the Fagerström score for physical dependence on nicotine were recorded.

Recent in utero exposure of newborns was evaluated using urinary cotinine concentrations in newborns and cord blood cotinine levels. All these variables were specific to smoking mothers and their offspring, and were strongly correlated with one another (Table 4).

Characteristics of the newborns. As previously described, newborns of HS mothers had significantly lower birth weights than newborns of NS, unexposed mothers $(3067 \pm 274 \mathrm{~g}$ versus $3472 \pm 286 \mathrm{~g} ; p=0.0003)$. No significant difference was found with regard to their cranial circumference or to their Apgar score at 1, 5 and $10 \mathrm{~min}$. Ten of the 17 newborns of HS mothers were breastfed, as were 11 of the 16 newborns of NS, unexposed mothers.

Neurologic scores. ANOVA of neurologic scores showed significant interactions, indicating nonsimilar changes in scores between exposed and unexposed newborns $(p<0.0001)$. Changes in repeated neurologic scores in newborns of HS mothers were significant $(p=0.05)$, whereas no significant change was found in repeated neurologic scores of newborns of NS mothers $(p=0.22)$.

On days 1 and 2, newborns of HS mothers had significantly lower scores for muscle tone, primary reflexes, and alertness than newborns of NS mothers. The total neurologic score on both day 1 and 2 was also significantly lower in newborns of HS mothers (Table 5).

On day 5, newborns of HS mothers had significantly lower scores for primary reflexes and alertness than did newborns of NS mothers. Differences persisted for muscle tone but without reaching statistical significance. The total neurologic score on

Table 3. Characteristics of the mothers

\begin{tabular}{|c|c|c|c|}
\hline & \multicolumn{3}{|c|}{$\begin{array}{l}\text { Smoking mothers Nonsmoking mothers } p \\
(n=17) \quad(n=16) \quad \text { value }\end{array}$} \\
\hline Age (y) & $30 \pm 6$ & $29 \pm 5$ & 0.69 \\
\hline First pregnancy $(n)$ & 3 & 4 & 0.68 \\
\hline First child $(n)$ & 3 & 5 & 0.44 \\
\hline Term of pregnancy (wk) & $38.5 \pm 0.5$ & $39.2 \pm 0.7$ & 0.003 \\
\hline No. cigarettes before pregnancy & $27 \pm 11$ & 0 & \\
\hline No. cigarettes during pregnancy & $18.6 \pm 5.7^{*}$ & 0 & \\
\hline
\end{tabular}

* Paired $t$ test on reduction, $p=0.025$. day 5 was significantly lower in newborns of HS mothers (Table 5).

The total neurologic score on day 1 was significantly lower than on day 5 in newborns of HS mothers, whereas it did not change significantly from day 1 to day 5 in newborns of NS mothers (Table 5).

Finnegan withdrawal scores. Daily values for the Finnegan score were calculated as means of scores recorded every $3 \mathrm{~h}$, every day. ANOVA for repeated measurements demonstrated a significant change in Finnegan scores according to the smoking status of the mother $(p=0.0004)$, whereas no change was found among the various measurements in each group ( $p=$ 0.65 and 0.64 , respectively).

Mean values for Finnegan scores at days 1, 2, and 4 were significantly higher in newborns exposed to maternal smoking during pregnancy than in unexposed newborns (Table 6).

Statistical analysis of neonatal CNS function and behavior in relation to markers of nicotine withdrawal. Multiple regression analysis of neurologic examination at day 1 of cord blood urinary cotinine, term of pregnancy, and breastfeeding showed that term of pregnancy and breastfeeding were no longer significant determinants for the neurologic examination at day 1 ( $p=0.93$ and 0.88 , respectively), whereas cord blood cotinine level remained significant $(p=0.0004)$.

Newborns' neurologic score at days 1 and 2 demonstrated a negative significant correlation to biologic markers of in utero exposure to maternal smoking (Table 7).

We found a significant correlation between Finnegan withdrawal score at day $2(r=0.41 ; p=0.02)$ and at day $4(r=$ $0.41 ; p=0.02)$ and variables of recent neonatal exposure ( $\log _{10}$ urinary cotinine in newborn, $\log _{10}$ cord blood cotinine, $\log _{10}$ urinary cotinine in mothers; Table 7).

Finnegan withdrawal score correlated with neurologic score at day $2(r=-0.55 ; p<0.001)$.

\section{DISCUSSION}

This prospective, two-group parallel study of repeated neurologic examinations and Finnegan withdrawal scores during the first $5 \mathrm{~d}$ of life was carried out on 17 consecutive normal newborns from HS mothers, compared with 16 consecutive normal newborns of NS, unexposed mothers. Neurologic scores at days 1,2, and 5 were significantly lower in newborns of HS mothers than in newborns of NS. The neurologic score improved significantly from day 1 to 5 in newborns of HS mothers, but not in newborns of NS mothers. In addition, at days 1, 2, and 4, the Finnegan withdrawal score was significantly higher in newborns of HS mothers than in newborns of NS mothers. Neurologic scores and Finnegan withdrawal scores were correlated with biologic markers of recent exposure to maternal cigarette smoke and to maternal score of physical dependence to nicotine (Fagerström score).

Nicotine withdrawal syndrome occurs in many adult smokers with a physical dependence on nicotine when they are acutely deprived of nicotine. Nicotine withdrawal syndrome is clinically different in adults from heroin withdrawal syndrome, and has only been reported more recently. The smoking mothers in our study are physically dependent on nicotine, as 
Table 4.Maternal smoking characteristics

\begin{tabular}{|c|c|c|c|}
\hline & $\begin{array}{l}\text { Smoking mothers } \\
(n=17)\end{array}$ & $\begin{array}{l}\text { Nonsmoking mothers } \\
\quad(n=16)\end{array}$ & $p$ value \\
\hline Smoking years $(n)^{*}$ & $16 \pm 5$ & $\ldots$ & \\
\hline Fagerström score* & $6.2 \pm 1.8$ & $\ldots$ & \\
\hline $\begin{array}{l}\text { Salivary thiocyanates } \dagger \\
(\mu \mathrm{g} / \mathrm{mL})\end{array}$ & $236.6 \pm 1.3$ & $58.9 \pm 1.9$ & 0.0001 \\
\hline \multicolumn{4}{|l|}{$\begin{array}{l}\text { Urinary cotinine concentration } \\
\quad(\mu \mathrm{g} / \mathrm{g} \text { creatinine }) \dagger\end{array}$} \\
\hline Newborns & $483.1 \pm 2.5$ & $43.6 \pm 1.5$ & 0.0001 \\
\hline Cord blood cotinine $\dagger(\mathrm{ng} / \mathrm{mL})$ & $85.8 \pm 3.4$ & Under the detection limit & \\
\hline
\end{tabular}

* Values are mean $\pm \mathrm{SD}$.

$\dagger$ Values are geometric mean \pm SD.

Table 5. Neurologic scores of newborn babies

\begin{tabular}{clccl}
\hline Time & \multicolumn{1}{c}{ Score } & $\begin{array}{c}\text { Smoking } \\
\text { mother } \\
(n=17)\end{array}$ & $\begin{array}{c}\text { Nonsmoking } \\
\text { mother } \\
(n=16)\end{array}$ & $p$ value \\
\hline Day 1 & Muscle tone & $7.9 \pm 1.5$ & $9.5 \pm 0.7$ & 0.001 \\
& Primary reflexes & $7.5 \pm 0.9$ & $9.0 \pm 0.7$ & 0.0001 \\
& Alertness & $6.8 \pm 1.4$ & $7.9 \pm 0.2$ & 0.004 \\
& Total neurologic & $22.3 \pm 2.3$ & $26.5 \pm 1.1$ & 0.0001 \\
& $\quad$ score & & & \\
Day 2 & Muscle tone & $8.2 \pm 1.7$ & $9.2 \pm 1.0$ & 0.05 \\
& Primary reflexes & $7.5 \pm 1.3$ & $9.2 \pm 0.7$ & 0.0001 \\
& Alertness & $6.7 \pm 1.1$ & $7.7 \pm 0.5$ & 0.001 \\
& Total neurologic & $22.4 \pm 3.3$ & $26.3 \pm 1.6$ & 0.0002 \\
& $\quad$ score & & & \\
Day 5 & Muscle tone & $8.6 \pm 1.5$ & $9.1 \pm 1.1$ & 0.22 \\
& Primary reflexes & $8.3 \pm 1.2$ & $9.4 \pm 0.5$ & 0.002 \\
& Alertness & $7.4 \pm 0.7$ & $7.9 \pm 0.2$ & 0.01 \\
& Total neurologic & $24.3 \pm 2.1 *$ & $26.5 \pm 1.5$ & 0.002 \\
& score & & & \\
\hline
\end{tabular}

* Neurologic score $v s$ day $1, p=0.05$.

Table 6. Finnegan score

\begin{tabular}{cccc}
\hline $\begin{array}{c}\text { Finnegan } \\
\text { score }\end{array}$ & $\begin{array}{c}\text { Smoking mother } \\
(n=17)\end{array}$ & $\begin{array}{c}\text { Nonsmoking } \\
\text { mother } \\
(n=16)\end{array}$ & $p$ value \\
\hline Day 1 & $4.5 \pm 2.1$ & $3.2 \pm 1.4$ & 0.05 \\
Day 2 & $4.7 \pm 1.7$ & $3.1 \pm 1.1$ & 0.002 \\
Day 3 & $3.8 \pm 1.5$ & $3.0 \pm 1.3$ & 0.13 \\
Day 4 & $4.7 \pm 2.1$ & $2.9 \pm 1.4$ & 0.007 \\
\hline
\end{tabular}

demonstrated by their high Fagerström scores. Fetal exposure is demonstrated by the presence of cotinine in the cord blood and in the newborns' urine.

Withdrawal syndrome in newborns passively addicted in utero to substances of abuse has been well characterized with opiates. Previous studies have shown that the withdrawal syndrome was more likely to occur in newborns of heroinaddicted mothers if the maternal dose had been high, if the last dose had been taken $24 \mathrm{~h}$ before the time of birth, if the mother had been a long-term addict, and if the infant was born at term (19). In our study population, maternal dose had been high (mean of 27 cigarettes/d before pregnancy, 18.6 cigarettes/d during pregnancy) with long-term addiction (mean of $16 \mathrm{y}$ ). In addition, the last dose had been taken less than $24 \mathrm{~h}$ before birth, as suggested by the high levels of cotinine measured in the cord blood.
Indeed, nicotine has been present at all stages of development of the CNS of newborns of nicotine-addicted mothers. Withdrawal from a substance that has been present during CNS development is likely to be different from withdrawal in adults, in which the drug has been initiated in a fully developed brain. Given the high prevalence of smoking during pregnancy, we know that no dramatic symptoms comparable to heroin withdrawal take place in newborns of smoking mothers. The accuracy of our observations may also be limited by the instrument used to evaluate withdrawal in newborns, which has been designed to evaluate opiate withdrawal.

Recent data from fetal behavioral studies indicate that fetal activity is significantly lower in fetuses chronically exposed to maternal smoking than in unexposed control fetuses (24). In addition (25), fetuses exposed to nicotine have been shown to have an altered neurobehavioral profile. The effect of acute cessation of exposure to maternal smoking on fetal behavior has not been investigated. Recent studies of cocaine-exposed newborns have regarded their neurobehavioral abnormalities as persistent cocaine effect rather than withdrawal symptoms (13). However, the short half-life of nicotine and the significant improvement of the neurologic score between days 1 and 5 only in nicotine-exposed babies suggest a withdrawal process.

The serial neurologic examinations are of major value, when carefully and thoughtfully performed by the same clinician. Even if the predictive power of isolated neurologic signs in the newborn period is not great, the value of combining abnormal signs has been fully recognized in previous studies (26).

Because 10 of the 17 smoking mothers were breastfeeding, the urinary cotinine concentration in their newborn babies was possibly influenced by digestive absorption of nicotine present in mother's milk. Previous studies carried out in newborns found no correlation between nicotine and cotinine concentrations in the newborn's urine samples and the amount of nicotine present in the mother's milk (27). In addition, a supplement of nicotine would decrease any withdrawal effect. In this study, the influence of nicotine supply through breastfeeding was shown to be not significant using multiple linear regression.

Although most smoking mothers had smoked their first cigarette a few hours after birth, as suggested by their $\mathrm{CO}$ level in expired air (28), the nonsmoking policy of the maternity ward was carefully enforced, ensuring that the mothers did not 
Table 7. Correlations between clinical characteristics of newborns (neurologic score and Finnegan withdrawal score) and markers of fetal exposure to nicotine and of maternal smoking

\begin{tabular}{|c|c|c|c|c|c|c|c|}
\hline $\begin{array}{c}\text { Monitoring } \\
\text { maternal } \\
\text { smoking }\end{array}$ & Neurologic day 1 & Neurologic day 2 & Neurologic day 5 & Finnegan day 1 & Finnegan day 2 & Finnegan day 3 & Finnegan day 4 \\
\hline \multicolumn{8}{|l|}{ Cotinine* } \\
\hline Cord blood & $-0.753(p<0.001)$ & $-0.585(p<0.001)$ & $-0.520(p<0.001)$ & $0.284(p=0.14)$ & $0.529(p=0.002)$ & $0.316(p=0.09)$ & $0.465(p=0.01)$ \\
\hline Urinary baby & $-0.648(p<0.001)$ & $-0.595(p<0.001)$ & $-0.523(p=0.002)$ & $0.185(p=0.31)$ & $0.471(p=0.006)$ & $0.315(p=0.07)$ & $0.441(p=0.01)$ \\
\hline Urinary mother & $-0.606(p<0.001)$ & $-0.605(p<0.001)$ & $-0.529(p=0.002)$ & $0.146(p=0.43)$ & $0.489(p=0.004)$ & $0.172(p=0.35)$ & $0.433(p=0.01)$ \\
\hline $\begin{array}{l}\text { Thiocyanates* } \\
\text { salivary, mother }\end{array}$ & $-0.658(p<0.001)$ & $-0.500(p=0.005)$ & $-0.476(p=0.009)$ & $0.247(p=0.20)$ & $0.427(p=0.02)$ & $0.187(p=0.34)$ & $0.419(p=0.02)$ \\
\hline $\mathrm{CO}^{*}$-mother & $-0.680(p<0.001)$ & $-0.683(p<0.001)$ & $-0.461(p=0.007)$ & $0.078(p=0.69)$ & $0.398(p=0.02)$ & $0.087(p=0.63)$ & $0.324(p=0.07)$ \\
\hline $\begin{array}{l}\text { Fagerström } \\
\text { score-mother }\end{array}$ & $-0.689(p<0.001)$ & $-0.628(p<0.001)$ & $-0.421(p=0.01)$ & $0.294(p=0.09)$ & $0.533(p=0.001)$ & $0.138(p=0.45)$ & $0.420(p=0.01)$ \\
\hline
\end{tabular}

* Expressed on a $\log _{10}$ scale.

smoke during labor and that the newborns were not exposed to environmental tobacco smoke. The mean duration of labor was higher than $8 \mathrm{~h}$. The half-life of maternal $\mathrm{COHb}$ being about $3 \mathrm{~h}$ (29), that of the newborn is considered longer (30); therefore a possible influence of $\mathrm{COHb}$ on neurologic score at day 1 cannot be excluded. In this study, we did not measure $\mathrm{COHb}$ in the cord blood. However, data from previous studies, measuring maternal and fetal $\mathrm{COHb}$ during pregnancy, indicate a mean fetal level of $4.5 \pm 3.1 \%$ and a ratio of fetal to maternal $\mathrm{COHb}$ of $1.32 \pm 0.61$, and demonstrate strong direct associations of fetal and maternal levels of $\mathrm{COHb}$ and cotinine (31).

The differences in neurologic scores in the newborns might have been influenced by the difference of $5 \mathrm{~d}$ in the term of pregnancy between the two groups; this factor was not a significant determinant of neurologic score when compared with markers of nicotine exposure, using multiple linear regression.

Neurologic scores and Finnegan withdrawal scores in newborns of HS mothers do not normalize at day 5. However, we do not have information about the evolution of Finnegan score and neurologic score after the fifth day of life, because the mothers and their babies were discharged from the maternity ward on the fifth day after birth. Thus, we do not have information about the length of nicotine withdrawal symptoms in neonates.

The small number of neonates and mothers in this study did not allow us to include other important variables in our analysis, such as socioeconomic determinants of maternal smoking. The mothers' level of education was, however, comparable between both groups.

\section{CONCLUSIONS}

Thus, our data strongly suggest that nicotine withdrawal symptoms, even discrete, are present in newborns of HS mothers. This conclusion supports the hypothesis that fetal passive addiction to nicotine occurs during pregnancy in HS.

Acknowledgments The authors thank the mothers and the nursing staff of the obstetric ward at the Clinique St-Pierre for their efficient help, and Sue Black for reviewing language issues.

\section{REFERENCES}

1. Stolerman IP, Jarvis MJ 1995 The scientific case that nicotine is addictive. Psychopharmacology 117:2-10

2. Hughes JR, Higgins ST, Bickel WK 1994 Nicotine withdrawal versus other drug withdrawal syndromes: similarities and dissimilarities. Addiction 89:1461-1470

3. Clarke PB 1992 Recent advances in understanding the actions of nicotine in the central nervous system. J Natl Cancer Inst Monogr 2:229-238

4. Schmidt BL, Tambeli CH, Gear RW, Levine JD 2001 Nicotine withdrawal hyperalgesia and opioid-mediated analgesia depend on nicotine receptors in the nucleus accumbens. Neuroscience 106:129-136

5. Owen L, McNeill A, Callum C 1998 Trends in smoking during pregnancy in England, 1992-1997: quota sampling surveys. BMJ 317:728-730

6. Smith GC, Pell JP 2001 Teenage pregnancy and risk of adverse perinatal outcomes associated with first and second births: population based retrospective cohort study. BMJ 323:476-481

7. Klesges LM, Johnson KC, Ward KD, Barnard M 2001 Smoking cessation in pregnant women. Obstet Gynecol Clin North Am 28:269-282

8. Picciotto MR, Zoli M, Lena C, Bessis A, Lallemand Y, LeNovere N, Vincent P, Pich EM, Brulet P, Changeux JP 1995 Abnormal avoidance learning in mice lacking functional high-affinity nicotine receptors in the brain. Nature 374:65-67

9. Hellstrom-Lindahl E, Seiger A, Kjaeldgaard A, Nordberg A 2001 Nicotine induced alterations in the expression of nicotinic receptors in primary cultures from human prenatal brain. Neuroscience 105:527-534

10. Koren G 1995 Fetal toxicology of environmental tobacco smoke. Curr Opin Pediatr 7:128-131

11. Kyerematen GA, Vesell ES 1991 Metabolism of nicotine. Drug Metab Rev 23:3-41

12. Lambers DS, Clark KE 1996 The maternal and fetal physiologic effects of nicotine. Semin Perinatol 20:115-126

13. American Academy of Pediatrics Committee on Drugs 1998 Neonatal drug withdrawal. Pediatrics 101:1079-1088

14. Picone TA, Allen LH, Olsen P, Ferris ME 1982 Pregnancy outcome in North American women. II. Effects of diet, cigarette smoking, stress, and weight gain on placentas and on neonatal physical and behavioral characteristics. Am J Clin Nutr 36:1214-1224

15. Garcia-Algar O, Puig C, Mendez C, Vall O, Pacifici R, Pichini S 2001 Neonatal nicotine withdrawal syndrome. J Epidemiol Community Health 55:687-688

16. Hasselmeyer EG, Meyer MB, Longo LD 1983 Pregnancy and infant health. In: The Health Consequences of Smoking for Women: A Report of the Surgeon General. US Government Printing Office, Washington, DC, pp 189-250

17. Slotkin TA, Lappi SE, Seidler FJ 1993 Impact of fetal nicotine exposure on development of rat brain regions: critical sensitive periods or effects of withdrawal. Brain Res Bull 31:319-328

18. Amiel-Tison C 1968 Neurological evaluation of the maturity of the newborn infants. Arch Dis Child 43:89-93

19. Volpe JJ 1995 The neurological examination: normal and abnormal features. In: JJ Volpe (ed) Neurology of the Newborn, 3rd Ed. WB Saunders, Philadelphia, pp 95-171

20. Finnegan LP 1985 Neonatal abstinence. In: Nelson N (ed) Current Therapy in Neonatal-Perinatal Medicine. Mosby, St. Louis, pp 262-270

21. Heatherton TF, Kozlowski LT, Frecker RC, Fagerström KO 1991 The Fagerström test for nicotine dependence: a revision of the Fagerström tolerance questionnaire. Br J Addict 86:1119-1127

22. Lequang Thuan NT, Migueres ML, Roche D, Roussel G, Mahuzier G, Chretien J, Ekindjilan OG 1989 Elimination of caffeine interference in HPLC determination of urinary nicotine and cotinine. Clin Chem 35/7:1456-1459

23. Bowler RG 1944 The determination of thiocyanate in blood serum. Biochemistry 38:385-388

23a. Suresh S, Anand KJS 1998 Opioid tolerance in neonates: mechanisms, diagnosis, assessment, and management. Semin Perinatol 22:425-433

24. Coppens M, Vindla S, James DK, Sahota DS 2001 Computerized analysis of acute and chronic changes in fetal heart rate variation and fetal activity in association with maternal smoking. Am J Obstet Gynecol 185:421-426 
25. Gingras JL, O'Donnell KJ 1998 State control in the substance-exposed fetus 1 . The fetal neurobehavioral profile: an assessment of fetal state, arousal, and regulation competency. Ann NY Acad Sci 846:262-276

26. Nelson KB, Ellenberg JH 1979 Neonatal signs as predictors of cerebral palsy. Pediatrics 64:224-232

27. Dahlstrom A, Lundell B, Curvall M, Thapper L 1990 Nicotine and cotinine concentrations in the nursing mother and her infant. Acta Paediatr Scand 79:142-147

28. Jarvis MJ, Russell MA, Saloojee Y 1980 Expired air carbon monoxide: a simple breath test of tobacco smoke intake. BMJ 281:484-485
29. Deller A, Stenz R, Forstner K, Konrad F 1992 The elimination of carboxyhemoglobingender-specific and circadian effects. Infusionsther Transfusionsmed 19:121-126

30. Bureau MA, Shapcott D, Berthiaume Y, Monette J, Blouin D, Blanchard P, Begin R 1983 Maternal cigarette smoking and fetal oxygen transport: a study of P50, 2,3diphosphoglycerate, total hemoglobin, hematocrit, and type $\mathrm{F}$ hemoglobin in fetal blood. Pediatrics 72:22-26

31. Hayde M, Bernaschek G, Stevenson DK, Haddow JE, Widness JA 1999 Antepartum fetal and maternal carboxyhemoglobin and cotinine levels among cigarette smokers. Acta Paediatr 88:327-331 